\title{
Approximation schemes for the generalized geometric problems with geographic clustering
}

Citation for published version (APA):

Grigoriev, A., \& Feremans, C. (2004). Approximation schemes for the generalized geometric problems with geographic clustering. METEOR, Maastricht University School of Business and Economics. METEOR Research Memorandum No. 034 https://doi.org/10.26481/umamet.2004034

Document status and date:

Published: 01/01/2004

DOI:

10.26481/umamet.2004034

Document Version:

Publisher's PDF, also known as Version of record

\section{Please check the document version of this publication:}

- A submitted manuscript is the version of the article upon submission and before peer-review. There can be important differences between the submitted version and the official published version of record.

People interested in the research are advised to contact the author for the final version of the publication, or visit the DOI to the publisher's website.

- The final author version and the galley proof are versions of the publication after peer review.

- The final published version features the final layout of the paper including the volume, issue and page numbers.

Link to publication

\footnotetext{
General rights rights.

- You may freely distribute the URL identifying the publication in the public portal. please follow below link for the End User Agreement:

www.umlib.nl/taverne-license

Take down policy

If you believe that this document breaches copyright please contact us at:

repository@maastrichtuniversity.nl

providing details and we will investigate your claim.
}

Copyright and moral rights for the publications made accessible in the public portal are retained by the authors and/or other copyright owners and it is a condition of accessing publications that users recognise and abide by the legal requirements associated with these

- Users may download and print one copy of any publication from the public portal for the purpose of private study or research.

- You may not further distribute the material or use it for any profit-making activity or commercial gain

If the publication is distributed under the terms of Article $25 \mathrm{fa}$ of the Dutch Copyright Act, indicated by the "Taverne" license above, 


\title{
Approximation schemes for the generalized geometric problems with geographic clustering
}

\author{
C. Feremans* A. Grigoriev ${ }^{\dagger}$
}

\begin{abstract}
This paper is concerned with polynomial time approximations schemes for the generalized geometric problems with geographic clustering. We illustrate the approach on the generalized traveling salesman problem which is also known as Group-TSP or TSP with neighborhoods. We prove that under the condition that all regions are non-intersecting and have comparable sizes and shapes, the problem admits PTAS. To derive a PTAS we extend the algorithm by Arora [2]. This extension involves the dissection mechanism and solution of the selection problem. We observe that the results are applicable to many generalized geometric problems, to other Minkowski norms, and to other fixed dimensional spaces.
\end{abstract}

\section{Introduction}

Problem Statement. We consider the following generalization of the classic Euclidean Traveling Salesman Problem (TSP). Assume that a salesman has to visit $k$ customers. Each customer has a set of specified locations in the plane (referred to as a region) where the customer is willing to meet the salesman. The objective is to find a shortest salesman tour that visits each of these customers. If a region is a single point, the described problem becomes the classic TSP.

The described generalization of TSP is known as the Generalized TSP, or the Group-TSP, or the TSP with neighborhoods. For short we shall refer to this problem as to GTSP. In the similar way we can define the generalizations for many other geometric optimization problems, for instance, Minimum Spanning Tree, Minimum Steiner Tree, Minimum $k$-Connected Subgraph, and many others.

Related Work. Traditionally, TSP attracts attention of many researchers in combinatorial optimization. The problem is known to be $N P$-hard. In the late nineties it has been shown that TSP and many other geometric optimization problems admit polynomial time approximation schemes (PTAS), see Arora [1] and Mitchell [5].

\footnotetext{
${ }^{*}$ FdEWB/KE, P.O.Box 616, 6200 MD, Maastricht, The Netherlands, E-mail: c.feremans@ke.unimaas.nl

${ }^{\dagger}$ FdEWB/KE, P.O.Box 616, 6200 MD, Maastricht, The Netherlands, E-mail: a.grigoriev@ke.unimaas.nl
} 
For GTSP it is known that the problem cannot be efficiently approximated within any constant factor unless $P=N P$, see [6]. Constant factor approximations were developed for the special cases where neighborhoods are disjoint convex fat objects [3], and where the diameter of neighborhoods are comparable [4]. For the case where the neighborhoods are pairwise disjoint unit disks Dumitrescu and Mitchell developed a PTAS [4].

Our results. In this paper we consider the special case of GTSP where the regions are non-intersecting and have comparable sizes and shapes. More precisely, the clustering is defined by a collection of $k$ simple polygons in the plane satisfying the following properties. Two polygons may intersect each other only on the boundaries. Every polygon contain a disk of diameter $q$ and the perimeter of each polygon is bounded from above by $c q$ where $c$ is a constant. In the interiors of these polygons $n$ points are distributed in such a way that each polygon contains at least one of the given points. The points belonging to the same polygon form a region. We associate the polygons with countries, the points with cities, and we refer to the regions as to geographic clusters.

We prove that GTSP restricted to the geographic clustering admits a PTAS. This result generalizes the PTAS for pairwise disjoint unit disks by Dumitrescu and Mitchell [4] in two directions. First, we allow a bigger variety of shapes and sizes of the regions. Second, we allow regions to be finite sets and for every region we solve the selection problem, namely, we choose the city to be visited.

Furthermore, our results are based on techniques different from m-guillotine method used in [4]. To derive a PTAS for GTSP with geographic clustering we extend the randomized dissection method presented in Arora [2]. We introduce a new dissection technique which can be used to construct PTAS for many generalized geometric problems with geographic clustering. In contrast to [2] where the level lines in the dissection are straight, the new dissection is based on the curved (piece-wise linear) level lines. We also adopt the dynamic programming routine from [2] to solve the selection problems in the regions.

Finally, we observe that our algorithm is applicable to generalized versions of many geometric optimization problems listed in [2]. We also observe that the methodology is applicable to other Minkowski norms and to other fixed dimensional spaces which also extends the results from [4].

\section{PTAS for GTSP with geographic clustering}

To obtain a PTAS for GTSP with geographic clustering we follow the Arora's PTAS [2] making the following changes:

1. Curved dissection. Straight level lines in the dissection could cut a polygon into parts. This causes the problem that for a cut polygon we cannot decide to which node of the dissection tree it belongs. We fix this problem by curved dissection. Assume that a horizontal line in the dissection cuts some polygon into two or more parts, say "north" and "south". In this case, we redefine the level line as follows. Let the level line follow the boundary of the "south" leaving the entire polygon in the "north", see Figure 1. Similarly, we change the vertical level lines leaving 
the cut polygons in the "west". Doing the curved dissection we uniquely define the places of cut polygons in the 4-ary dissection tree.

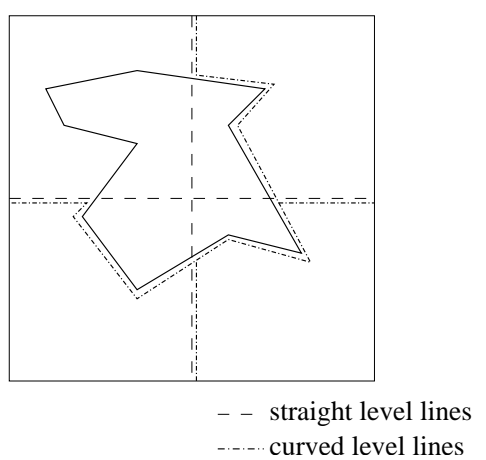

Figure 1: Curved dissection

2. Early stop. If the curved dissection goes too deep, two sequential curved level lines may have a common segment which again can cause the problem when deciding to which node of the dissection tree the polygon belongs. To avoid common segments we stop the dissection when the distance between two sequential straight level lines is $c q$. So, with the early stop and the curved dissection we uniquely define the places for all polygons in the 4-ary dissection tree.

3. Reduced random shifts. By early stop in the randomized dissection it is sufficient to consider the random horizontal shifts $a$ and random vertical shifts $b$ such that both, $a$ and $b$, are divisible by $c q$.

4. Portals multiplicities. Since we allow curved level lines, the perimeter of the "squares" in the dissection increases. To keep the inter-portal distances unchanged on the curved level lines, we have to enlarge the number of portals on the perimeter of the "squares". From the condition that perimeter of any polygon is at most $c q$, we derive that the perimeter of any "square" in the curved dissection is at most $4 c^{2} / \pi$ times bigger than the perimeter of the corresponding square in the straight dissection. Therefore, it is sufficient to multiply the portal parameter by the constant factor $4 c^{2} / \pi$.

5. Solution of the selection problem. From early stop and condition that each polygon contains a disk of diameter $q$, we derive that in the leaves of the revised 4-ary dissection tree the number of polygons is at most $4 c^{2} / \pi$. Since the number of cities in each polygon is finite and we have to pick up only one city per polygon, for any leaf of the dissection tree we can effectively enumerate all possible arrangements for the cities to be visited.

For the revised algorithm we prove the Structure Theorem as in [2], and consequently we have the following theorem. 
Theorem 2.1. With probability at least 1/2 over the choice of the shifts a and $b$, the revised algorithm provides a portal respecting tour of length $(1+\varepsilon) O P T$ in time $O\left(n^{O\left(c^{2} / \varepsilon\right)}\right)$, where $\varepsilon>0$ is a required accuracy parameter, and $O P T$ is the optimum GTSP tour length.

To derandomize the algorithm we can, for instance, go through all choices for $a$ and $b$.

\section{References}

[1] S. Arora. Nearly linear time approximation schemes for Euclidean TSP and other geometric problems. JACM, 45 (1998) 1-30.

[2] S. Arora. Approximation schemes for NP-hard geometric optimization problems: A survey. Mathematical Programming 97 (2003) 43-69.

[3] M. de Berg, J. Gudmundsson, M. Katz, C. Levcopoulos, M. Overmars, A. van der Stappen. TSP with neighborhoods of varying size. In Proc. ESA (2002) 187-199.

[4] A. Dumitrescu, J.S.B. Mitchell. Approximation algorithms for TSP with neighborhoods in the plane. J. of Algorithms 48 (2003) 135 - 159.

[5] J.S.B. Mitchell. Guillotine subdivisions approximate polygonal subdivisions: A simple polynomial-time approximation scheme for geometric TSP, k-MST, and related problems. SIAM J. Comput. 28 (1999) 1298 -1309 .

[6] S. Safra, O. Schwartz. On the complexity of approximating TSP with neighborhoods and related problems. In Proc. ESA (2003) 446-458. 